\title{
Enhanced Wireless Control System for Smoke and Fire Detection
}

\author{
Toufiqul Islam, Syed Asif Abdullah, and Golam Sarowar
}

\begin{abstract}
This paper describes the design and engineering of a wireless control system for smoke and fire detection with alarming provision, sms sending and fire extinguishing by a vehicle. We chose the PIC microcontroller for the controlling of the system. The implemented design is so cheap and effective. The sms sending feature included in the design increases the reliability of the system so that it can notify the fire hazard when there is no person available nearby. The fire extinguishing vehicle is a unique feature and it gives a provision to extinguish fire during its very early stage. The design will increase the safety and reliability with reducing the risks to life and property.
\end{abstract}

Index Terms-Fire extinguishing vehicle, GSM technology, RF transmission, wireless control.

\section{INTRODUCTION}

A smoke detector or smoke alarm is a device that detects smoke and issues an alarm to alert nearby people that there is a potential fire. Smoke detectors can work by optical detection (photoelectric) or by physical process (ionization), but some smoke detectors also utilize both types of detector to increase the sensitivity to smoke [1]-[3]. In this paper, enhancement done on already available photoelectric smoke detector circuitry by integrating some distinct features like wireless technology, sms sending through gsm module and fire extinguishing vehicle [4]. This features increase the safety and reliability of the smoke and fire detection technology.

\section{SYSTEM OVERVIEW}

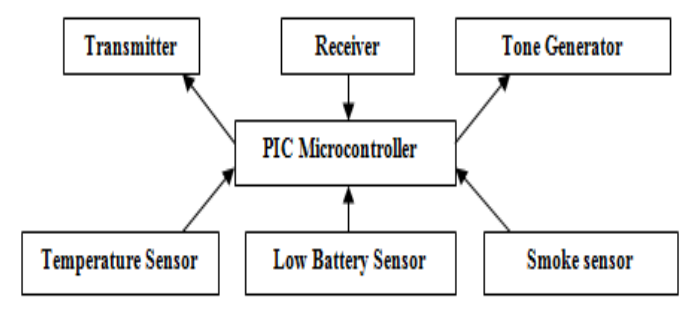

Fig. 1. System overview

The smoke detection system can detect smoke or high temperature (potential fire) and sets off appropriate alarm

Manuscript received October 25, 2012; revised November 29, 2012.

Toufiqul Islam is with the Atish Dipankar University of Science and Technology(ADUST)(e-mail: toufiq2650@yahoo.com).

Syed Asif Abdullah and Golam Sarowar are with the Islamic University of Technology (IUT), Dhaka, Bangladesh (e-mail: turjo16@yahoo.com, sarowarg@gmail.com). sound [5], [6]. It also transmit RF signal to the other smoke detector in the network. The detector capable of sounding four different alarms for smoke, temperature, low battery and receiver [7]. PIC microcontroller is the heart of the system.

\section{TEMPERATURE SENSOR}

The temperature sensor sends an analogue signal to the PIC microcontroller to set off the alarm when the temperature reaches $125^{\circ} \mathrm{F}$. The design consists of a temperature sensor (LM-35) whose output voltage is equal to $1^{\circ} \mathrm{F} / 10 \mathrm{mv}$.

$$
\begin{aligned}
& \text { Vtemp_threshold }=X^{*} 1^{\circ} \mathrm{F} / 10 \mathrm{mv} \\
& 125^{\circ} \mathrm{F}=X^{*} 1^{\circ} \mathrm{F} / 10 \mathrm{mv} ; x=1.25 \mathrm{~V}
\end{aligned}
$$

Based on these calculations performed in the PIC microcontroller code the temperature alarm is set off after the output voltage of the temperature sensor reaching appropriate threshold voltage. Voltage comparator (LM 393) is used whose output is connected to microcontroller. The Vin - of voltage comparator is connected to $1.25 \mathrm{~V}$ and $\mathrm{Vin}+$ is connected with temperature sensor schematic.

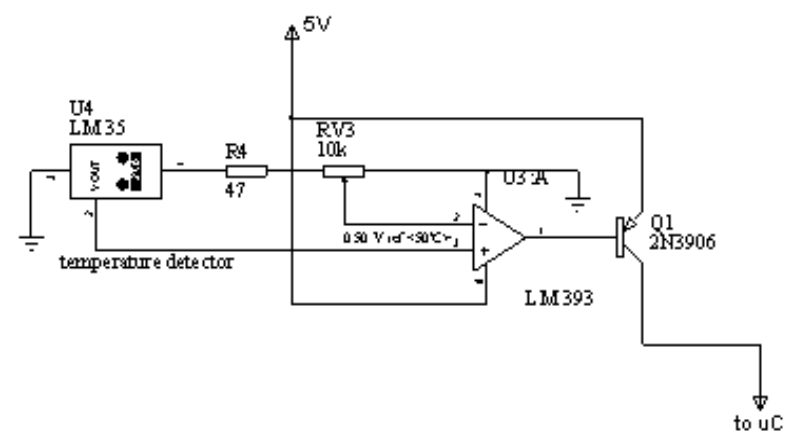

Fig. 2. Temperature sensor schematic

\section{SMOKE SENSOR}

The smoke sensor is a T-shaped chamber with an infrared LED placed in the left opening that emits a beam of light across the horizontal portion of the chamber. The right opening is open for smoke particles to enter as base opening for the phototransistor. The phototransistor generates a current when exposed to light. If there is no smoke present inside the chamber, the beam of light is emitted across the top of the T-shaped chamber. Thus, the phototransistor does not generate current as no light has hit it. When smoke particle enter the T-shaped chamber, however the beam of light is scattered by smoke particles. Subsequently, some of the light is directed down into the vertical portion of the T-shaped chamber and strikes the phototransistor. 


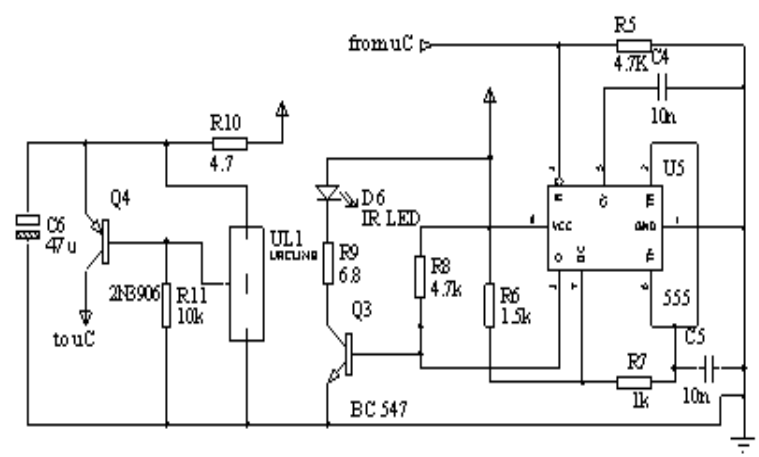

Fig. 3. Smoke sensor schematic

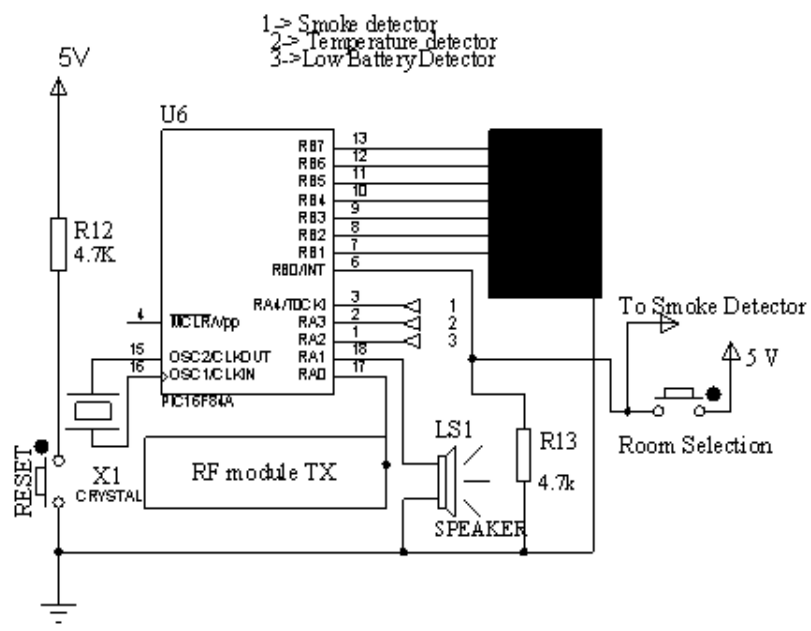

Fig. 4. Close view of microcontroller interfacing

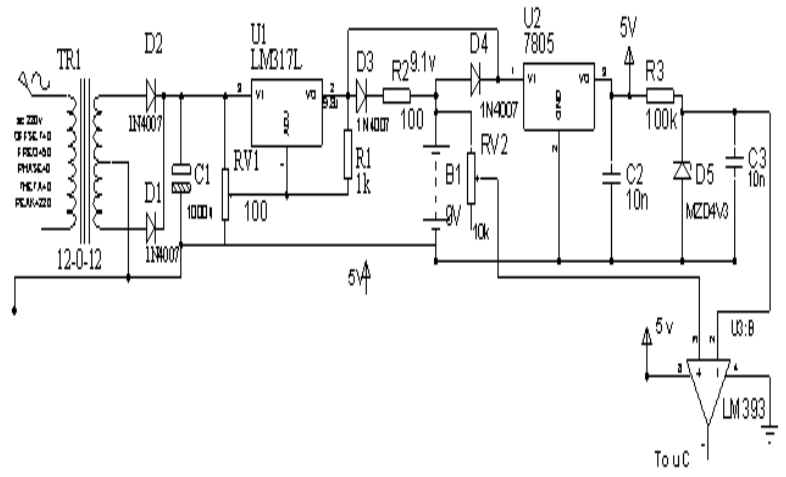

Fig. 5. Low battery sensor Schematic

\section{LOW BATTERY SENSOR}

The function of the low battery sensor schematic is to measure the amount of battery life remaining; when the battery life dips below $3.5 \mathrm{~V}$ the design enables smoke detector to emit the low battery alarm via the tone generator.

\section{TONE GENERATOR AND SPEAKER}

The tone generator and speaker module emits the appropriate sound determined by the PIC microcontroller. There are four distinct alarms [7]. The temperature detector alarm and smoke alarm both sound at $4 \mathrm{kHz}$; however the temperature alarm is sounded at a higher volume level. In addition, there is a detected signal alarm (smoke or fire detected at another detector) that sounds at $2 \mathrm{kHz}$. There is also a low battery alarm that sounds at $500 \mathrm{~Hz}$.

\section{RECEIVER}

The receiver (RMX-900-HP3) receives the signal from the transmitter of the other smoke detectors and relays that signal to the PIC microcontroller.

\section{PIC MICROCONTROLLER}

PIC microcontroller (PIC 16F84A) is the heart of the system. Microcontroller input comes from receiver, temperature sensor, smoke sensor, and low battery sensor as well as outputting the appropriate signal and bits to the tone generator and transmitter.

\section{TRANSMITTER}

The transmitter (TMX-900-HP3) sends a signal to the other smoke detectors in the network in order to alert them to set off the audible alarm.

\section{RF TRANSMISSION}

Radio frequency (RF) transmission uses radio waves like radio or television signals to transmit audio via a carrier from transmitter to receiver. The transmitter has an antenna usually attached to the transmitter unit, which needs to be positioned adequately cover the listening area. Transmitter and receiver communicate between them through Manchester coding for RF transmission. Manchester coding works on transitions from high to low (for bit 0 ) and low to high (for bit 1). The actual width of the pulses doesn't matter particularly (within reason).Packet system transmission in terms of reliability. The packet consists of a no. of different sections.

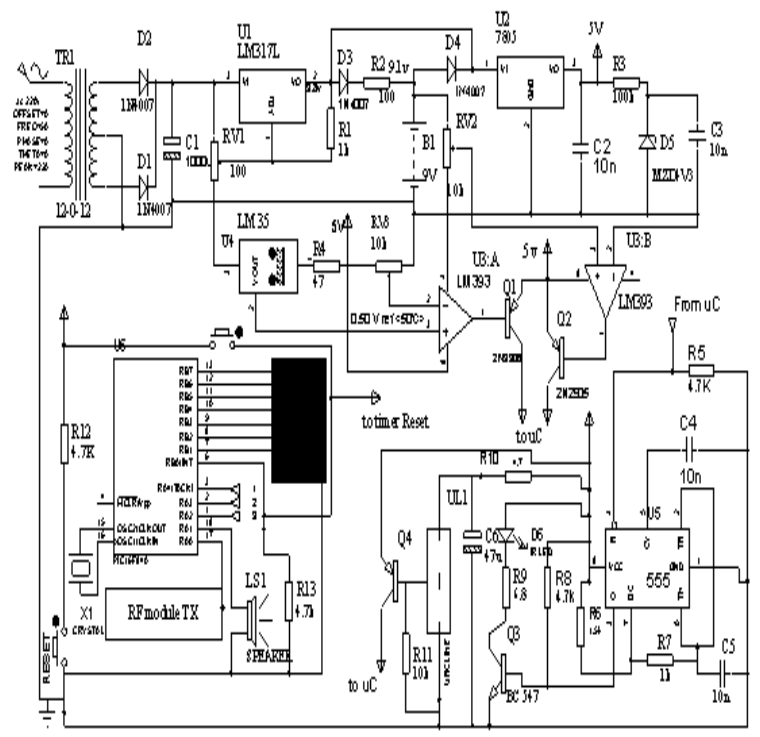

Fig. 6. Total circuit diagram of the remote sensor 
Header section- used to synchronize to the beginning of the packet. This consists of a row of 20 bit one's followed by a single bit zero. The long sequence of one's gives the receiver time to settle and the decoding software to synchronize.

Address- consists of 8 bit data in the byte followed by a single bit one and single bit zero. Receiver checks these bytes to make sure its intended for this receiver.

Data- this is same as address, 8 bits followed by a single bit one and a single bit zero.

Checksum- consists of 8 bits followed by a single bit one and a single bit zero. This byte makes sure that data the data is received correctly. If it fails data should be discarding.

Total of 52 bits to send just a 8 bits data byte. Two bytes will take 62 bits or four bytes will take 82 bits.

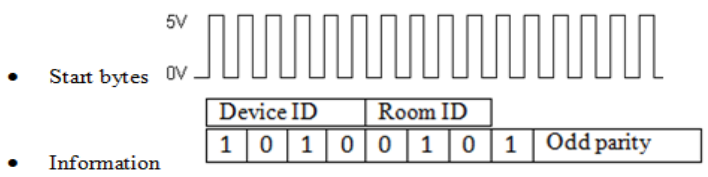

Fig. 7. RF transmission

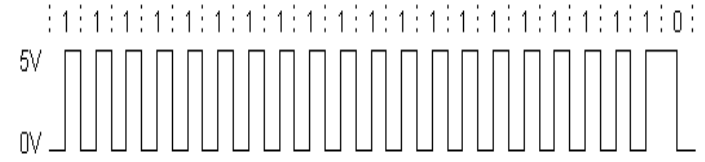

Fig. 8. Header bits

\section{SySTEM OVERVIEW OF SENDING SMS}

Block diagram of figure (9) shows the system overview of sending sms. It consists of wireless control smoke and fire detection module [8], computer, GSM module and a receiving mobile station.

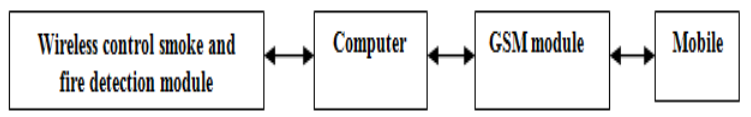

Fig. 9. Block diagram of sending SMS

\begin{tabular}{|l|l|}
\hline Command & Description \\
\hline AT & Check if the serial interface and GSM module working \\
\hline ATE0 & Tum echo off, less traffic on signal line \\
\hline AT +CNMI & Display of new \\
\hline AT + CPMS & Selection of sms memory \\
\hline AT +CMGF & sms starting point, how they are compressed \\
\hline AT +CMGR & Read new message from a given memory location \\
\hline AT +CMGS & Send message to a given recipient \\
\hline AT +CMGD & Delete message \\
\hline
\end{tabular}

Fig. 10. AT command set

After detecting smoke or fire the detector module will activate a relay by the help of the PIC microcontroller connected to the module. The relay is connected to the PC via parallel port. The incoming signal is read by the parallel port status register address. The programme then sends a specified message to a particular mobile station via the GSM module connected to the computer's com port. The protocol used by the GSM modules for set up and control is based on the Hayes AT-Command set. Since the main objective for this application note is to show how to send and receive text messages, only a subset of AT-Command set needs to be implemented.

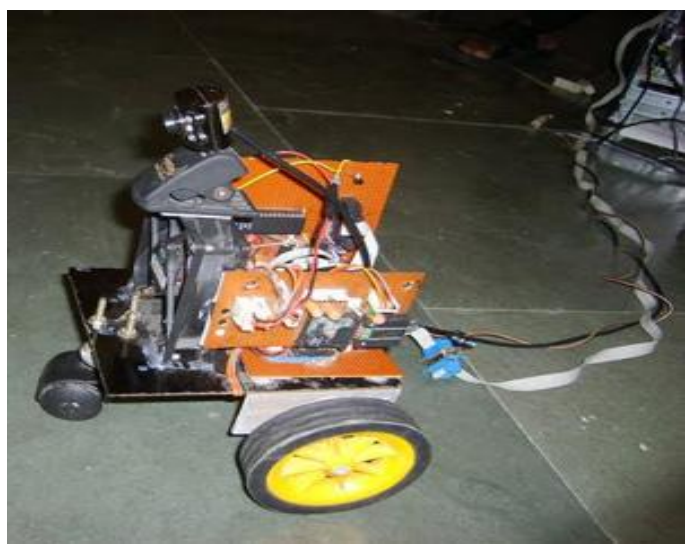

Fig. 11. Fire extinguishing vehicle

\section{Fire EXTINGUishing VEHICLE}

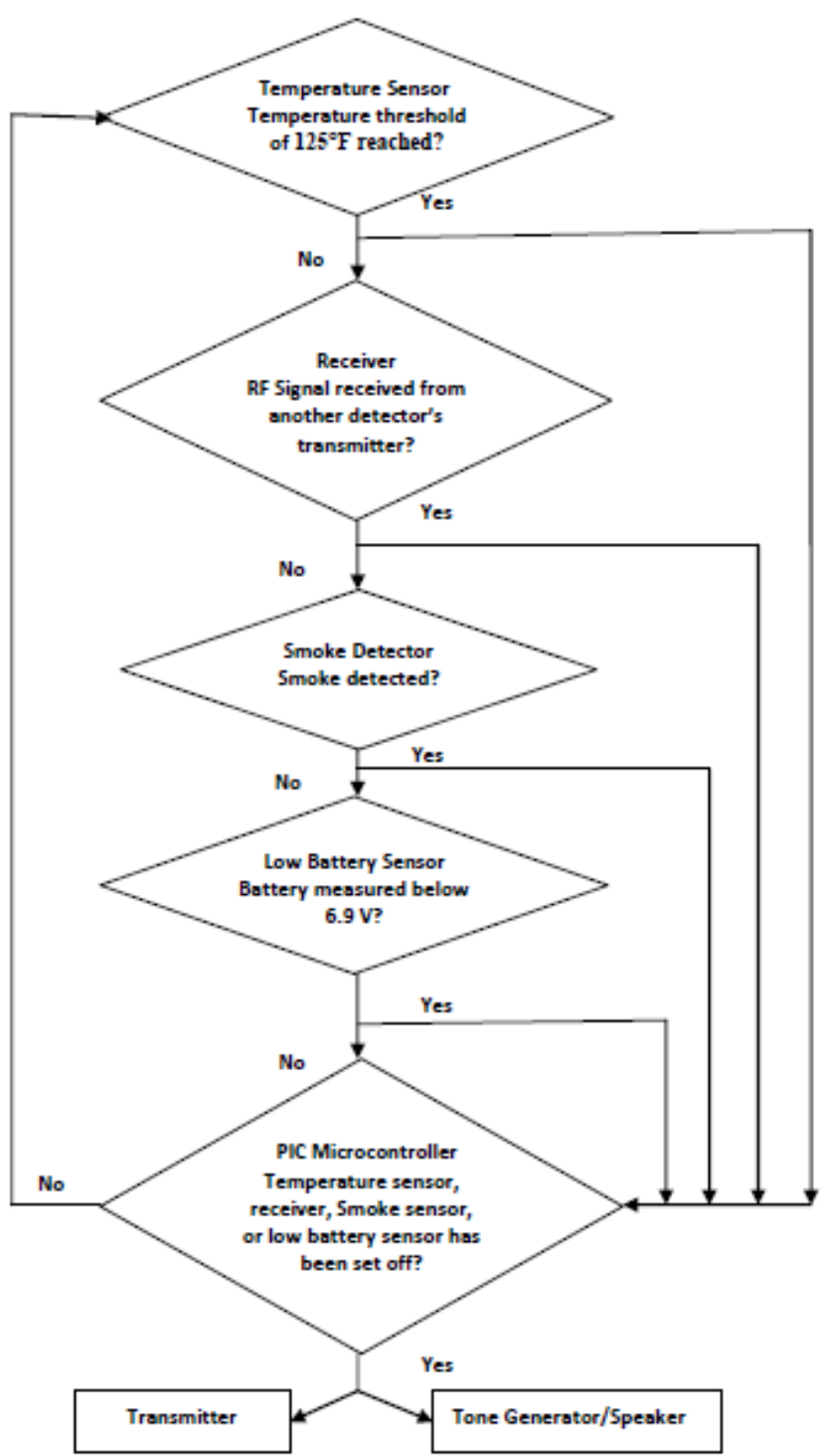

Fig. 12. Flowchart for the PIC microcontroller 
A microcontroller (atmega 16) based fire extinguishing vehicle can be used to extinguish the fire. Someone can also operate and control the vehicle. This vehicle has different features and it will operate after the smoke detector network detects smoke or fire. Different features of the fire extinguishing vehicle and their functions are given below.

Fire Extinguisher- The vehicle carrying the fire extinguisher locates the fire and extinguishes it. It follows the predefined path to find out the origin of the fire.

Manual Remote Control- A manual remote control can navigate the vehicle and do the assigned purposes.

Obstacle Detection- It emits an infrared light. If there is any obstacle, the light will be reflected and detector will sense it.

Temperature Sensor- By using a temperature sensor the vehicle can sense the temperature around it. By using this facility it can find out the distance of the fire and safety move from the endangered place.

Image Processing- A webcam can be fitted at the top of the vehicle to take the image of the location and further processing can be done to find out the location and distance of the origin of the fire.

\section{CONCLUSION}

This paper enhanced the smoke and fire detection technology to save lives of people and property more and more. The heart of the system is a PIC microcontroller which is very cheap now a day. The fire extinguishing vehicle is controlled by an atmega 16 microcontroller which is also very cheap and easily programmable. The sms sending feature make the system more reliable and more sophisticated in terms of life safety as it is done by the help of a gsm module. The use of photoelectric smoke detector in the design makes the system more reliable for detecting smouldering fire. In addition one can use ionized smoke detector instead of optical smoke detector for more fast operation and sensitivity. Enhancement work can be done on point out the origin of fire. We have introduced the webcam facility. So better image processing methods can be included to find out the exact point from where fire has been originated.

\section{REFERENCES}

[1] A. Keller et al. "Open photo acoustic sensor as smoke detector," Journal of sensor and Actuators B; Chemical, vol. 104, no. 1, 3 January 2005, pp.1-7.
[2] A. Z. Adamyan et al. "Smoke Sensor with overcoming of humidity cross-sensitivity," Journal of sensor and Actuators B; Chemical, vol. 93, no. 1-3, 1 August 2003 , pp.416-421

[3] O. V. Sulima et al, "Low voltage AlGaAsSb/InGaAsSb/Gab avalanche photo-detector," IEEE Proceeding -Optoelectronics, vol.151, no. 1, February 2004 , pp. 1-5.

[4] H. A. Kadir, N. Al-Khatib, O. Al Shamma, and M. Saleh. A Smoke Detection System Using WirelessSensorNetwork. [Online]. Available: http://www.scribd.com/doc/38356223/A-Smoke-Detection-System-Us ing-Wireless-Network

[5] Sensor Network Operation. [Online]. Available: http://intel.com/research/exploratory/

[6] Sensornetwork. [Online]. Available: sensornetwork_operation.htm.

[7] System Smoke Detector. [Online]. Available: http://www.systemsensor.com/pdf/A05-1003.pdf

[8] D. T. Gottuk, M. J. Peatross, R. J. Roby, and C. L. Beyler, "Advanced Fire Detection Using Multi-Signature Alarm Algorithm," Fire Suppression and Detection Research Application Symposium, February 24-26, 1999, Orlando. FL, pp. 140-149, 1999.

[9] Wireless Sensor Networks. [Online]. Available: http://webhosting.devshed.com/a/c/Web-Hosting-Articles/wireless-Se nsor-Network-pt-1-Introduction/

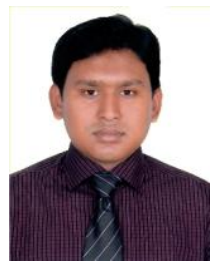

Toufiqul Islam was born in the city Lalmonirhat, Bangladesh in the year 1988. He received his B.Sc. Degree in Electrical and Electronic Engineering (EEE) from the department of EEE of Islamic University of Technology (IUT), Gazipur, Bangladesh in the year 2010

$\mathrm{He}$ is now working as a Lecturer of EEE at Atish Dipankar University of Science and Technology (ADUST). He is also working as an Adjunct Faculty of EEE at Ahsanullah University of Science and Technology (AUST). His research area includes Microcontroller based system design and Renewable energy arena.

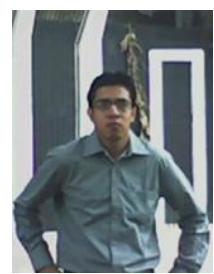

Syed Asif Abdullah was born in Dhaka, Bangladesh in the year 1988. He received his B.Sc. Degree in Electrical and Electronic Engineering (EEE) from the department of EEE of Islamic University of Technology (IUT), Gazipur, Bangladesh in the year 2010.

$\mathrm{He}$ is working as an Aircraft Maintenance Engineer (AME) at GMG Airlines Ltd. Along with this he is engaged in teaching at different Aeronautical institute. His research area includes Microcontroller based system design and Biomedical Signal processing.

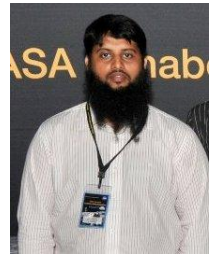

Golam Sarowar was born in the city Dhaka, Bangladesh in the year 1984. He received his B.Sc Degree in Electrical and Electronic Engineering (EEE) from the department of EEE of Islamic University of Technology (IUT), Gazipur, Bangladesh in the year 2005. He has completed his M.Sc. in EEE from Bangladesh University of Engineering and Technology (BUET), Dhaka, Bangladesh in the year 2009.

$\mathrm{He}$ is working as an Assistant Professor at Islamic university of Technology (IUT). His research area includes Microcontroller based system design and Power System Protection. 